\title{
DEBATES
}

\section{Represión y justicia en Venezuela en tiempos de protesta}

\author{
Repression and justice in Venezuela in times of protest
}

\section{Rogelio Perez-Perdomo}

\section{Resumen}

Entre febrero y mayo de 2014, las mayores ciudades venezolanas se vieron sacudidas por grandes manifestaciones públicas con una presencia muy alta de jóvenes, que protestaban contra la elevada criminalidad violenta, la escasez, la inflación y por lo que consideraban falta de futuro. Las manifestaciones fueron reprimidas con violencia, pela policía militar, causando medio centenar de muertos, millares de detenidos, más de un millar de heridos y lesionados y cerca de 2.500 personas sometidas a juicio penal. Varios dirigentes y alcaldes de la oposición se mantienen detenidos. En la represión intervinieron fuerzas parapoliciales y bandas armadas. El sistema de justicia ha colaborado en la masiva violación de los derechos humanos. El artículo analiza el significado de una represión tan masiva para el sistema jurídico y el estado.

\section{Palabras clave}

Protestas en Venezuela 2014; Represión y Sistema de Justicia; Sistema Jurídico; Estado Debilitado.

\section{Abstract}

Between February and May 2014, wide public demonstrations erupted mayor cities in Venezuela, when young people protested against violent criminality, scarcity of goods, inflation and a general perception of an uncertain future. They were violently repressed by the military police, the police and armed thugs. Fifty people died, many were injured or arrested, and about 2.500 were submitted to criminal procedure. A number of opposition leaders and mayors are still in prison. Prosecutors and judges have collaborated in the repression and have paid no attention to the massive violation of human rights. The article analyzes the meaning of such massive repression for the judicial system and the state.

\section{Keywords}

Venezuelan 2014 Protests; Repression and Justice System; Legal System; Weakened State. 


\section{Introducción}

El 12 de febrero de 2014 una enorme manifestación cruzó a Caracas para llegar a las oficinas del Ministerio Público y solicitar la libertad de los presos políticos, el fin de la inseguridad y la disolución de las bandas armadas del gobierno. En las principales ciudades de Venezuela hubo manifestaciones similares. Desde ese día en adelante, grandes manifestaciones políticas se sucedieron con frecuencia durante unos cuatro meses y generalmente terminaban en violencia cuando eran atacadas por la Guardia Nacional (la policía militar), otras policías y las bandas armadas del gobierno. En varias ciudades y en distintas oportunidades, opositores al gobierno construyeron barricadas (llamadas "guarimbas" en Venezuela) para protegerse de la Guardia Nacional, la Policía Nacional y de las bandas armadas, así se perturbo severamente la vida urbana. Los eventos ocurrieron en toda Venezuela y de hecho fueron más violentos en ciudades como San Cristóbal, Mérida y Valencia que en Caracas. En San Cristóbal, las manifestaciones comenzaron un poco antes y la resistencia civil fue más agresiva hasta el punto que el gobierno llegó a usar la aviación militar como una amenaza para la destrucción de las guarimbas. En resumen, ha habido decenas de muertos, centenares de heridos y propiedades destruidas ${ }^{1}$. Dos meses después, más de un millar de personas habían sido sometidas a juicio penal y más de un centenar estaban presas. En mayo de 2014, 2.463 personas estaban sometidas a juicios penales (VENEZUELA, 2014, p. 59)

La crisis fue considerada lo suficientemente importante para que la Unión de Repúblicas de América del Sur (UNASUR) enviara sus cancilleres a Caracas y un grupo de tres cancilleres (Brasil, Colombia y Ecuador) y el Nuncio Apostólico facilitaron los llamados diálogos de paz entre el gobierno y la oposición. El diálogo no produjo ningún fruto visible. Las manifestaciones políticas cesaron seguramente como consecuencia de la dura represión que fue desatada.

El origen de la crisis estuvo un año atrás, en la elección de Nicolás Maduro como Presidente de la República en abril de 2013. El gobierno tomó las medidas más populistas imaginables y usó abundantemente los recursos del estado para apoyar al candidato gubernamental. El árbitro electoral (Consejo Nacional Electoral - CNE) mostró clara parcialización por Maduro. Sin embargo el resultado fue muy cerrado y el candidato opositor Henrique Capriles solicitó el reconteo manual de los votos y la revisión de las actas de votación. La petición no fue atendida y Nicolás Maduro fue

\footnotetext{
${ }^{1}$ El Observatorio Iberoamericano de la Democracia (OID, 2014) da una cuenta muy detallada de los eventos del 12 de febrero 2014, con profusión de fotografías de personas golpeadas, torturadas o asesinadas.
} 
proclamado Presidente sin que la oposición aceptara los resultados. Hubo manifestaciones espontáneas de protesta que fueron reprimidas brutalmente ante lo cual el candidato derrotado prefirió cancelar las manifestaciones de protesta previstas.

El primer año de gobierno de Maduro ha sido especialmente adverso en sus resultados económicos y en la agravación de la crisis social. Inflación y escasez de productos básicos son los rasgos dominantes en lo económico. El gobierno ha acentuado el control de la televisión, los medios impresos y la mayor parte de las estaciones de radio están también controladas por el gobierno. A través de un estricto control de cambios prácticamente se impide la importación de papel para los periódicos que considera no amistosos. La situación social también se ha deteriorado. Los índices de violencia delictiva han mantenido su crecimiento ${ }^{2}$. Entre las nuevas víctimas de la violencia delictiva están los jóvenes estudiantes, pues los delincuentes no vacilan en ingresar a las universidades y colegios y atracar salones de clase. Sin duda, las bandas armadas del gobierno ${ }^{3}$, que se movilizan en motocicletas y gozan de impunidad, están identificadas como parte importante del problema de inseguridad.

La oposición estaba unificada en una organización de coordinación de los distintos partidos llamada Mesa de la Unidad Democrática (MUD). Dentro de ella, dos dirigentes de gran arrastre popular, Leopoldo López y María Corina Machado, preconizaron llamar a la protesta popular, mientras que la corriente mayoritaria había optado por un trabajo de fortalecimiento, lo que unido al debilitamiento del gobierno por sus disparatadas políticas económicas y sociales podría permitir una salida de éste en una próxima oportunidad electoral. La gigantesca manifestación del 12 de febrero fue un respaldo del pueblo opositor a la posición de López y Machado. Aun cuando los dirigentes opositores mantienen en declaraciones públicas los llamados a la

\footnotetext{
${ }^{2}$ Las cifras de delincuencia dejaron de publicarse regularmente en Venezuela. La tasa oficial de homicidios que el gobierno informa a Naciones Unidas es del orden de los 45 por 100.000 habitantes, pero el Observatorio Venezolano de la Violencia da cifras mucho más altas. Para 2013 sería de 75 por 100.000 habitantes. Aun la cifra oficial es una de las más altas en América Latina. El enorme incremento de los delitos violentos seguramente se debe a que el gobierno ha protegido bandas armadas (oficialmente llamadas "colectivos") cuya misión es proteger la revolución. Actúan como fuerzas de choque para atacar los actos de la oposición. En la práctica, y mientras no están desempeńando tales funciones, cometen delitos y se refugian en zonas de la ciudad que controlan donde no está permitido el ingreso de la policía o de miembros de otras bandas (BRICEÑO-LEÓN et al., 2012; PÉREZ-PERDOMO, 2012; ANDERSON, 2013).

${ }^{3}$ Estas bandas no están controlados por ningún cuerpo policial o militar sino por la Comisión de Seguridad y Defensa Integral del Partido Socialista Unido (PSUV), el partido de gobierno (VON BERGEN, 2014).
} 
unidad, la impresión es que las divergencias en la estrategia parecen haberla fracturado, al menos por el momento.

Por su parte, el gobierno entendió las protestas como un intento para derrocarlo. De allí su reacción, que quien no tenga en cuenta el contexto consideraría absurdamente desmesurada. En Chile y Brasil ha habido también manifestaciones de jóvenes, en ocasiones muy violentas, sin que esto haya generado una reacción comparable del gobierno. La intervención de los cancilleres y el Nuncio Apostólico ha obligado a moderar el aspecto más violento de la represión. Al menos cesaron los homicidios.

El foco del trabajo no es la crisis y sus posibles desenlaces sino la acción del sistema de justicia en relación con la represión desarrollada en estos meses y sus implicaciones para pensar el sentido del estado de derecho. Los acontecimientos han tenido amplia cobertura por la prensa, la televisión y demás medios a escala global ${ }^{4}$. El lector deberá tener en cuenta que se investiga sobre acontecimientos en desarrollo, respecto a los cuales no parece posible la neutralidad. El investigador ha hecho un esfuerzo en permanecer en la descripción y ha usado como fuentes principales la prensa diaria y publicaciones más o menos informales de Internet. Los acontecimientos replantean el sentido del derecho y del estado, lo que obliga a remontarse a la filosofía política y jurídica del siglo XVII. El conjunto de las organizaciones de derechos humanos de Venezuela publicaron el informe Venezuela 2014: Protestas y derechos humanos. Informe Febrero - Mayo 2014, sin que nadie apareciera como responsable de la publicación. Dado el contexto de represión, esta precaución no puede considerarse excesiva. En este trabajo usamos ese informe, pero hemos privilegiado la información periodística recogida en la medida en que avanzaba el conflicto.

En la primera parte, me concentraré en algunos eventos que son importantes para destacar el papel de la justicia. La segunda parte es analítica. Veremos qué queda del derecho y qué lección podemos sacar de un proyecto exitoso de destruir la independencia judicial y, en definitiva, el estado de derecho.

\footnotetext{
${ }^{4}$ El gobierno ha hecho esfuerzos importantes para limitar la información que se difunde. Un número de periodistas han sido heridos o puestos en prisión, sus cámaras fotográficas o filmadoras decomisadas o robadas. Patricia Janiot, una periodista importante de CNN, fue expulsada del país, y varios pasajes de una entrevista a Vargas Llosa fueron censurados, lo que obligó a la renuncia de la entrevistadora Shirley Varnagy a Globovisión (televisora privada pero controlada por el régimen).
} 


\section{Noticias del abismo}

El subtítulo puede parecer dramático, pero Venezuela vive un tiempo de violencia social y polarización política que no había vivido en su historia. El gobierno se proclama revolucionario y socialista. Controla todas las instituciones del estado, pero esto no ha producido un nuevo orden social sino más bien considerable desorden y caos. La mayor parte de la población sufre el temor a la delincuencia violenta, la escasez, la inflación y, en definitiva, la percepción de vivir en un sistema económico colapsado que no ofrece futuro alguna. Estos males afectan de manera más directa a los jóvenes. Es esto lo que explica la gran manifestación del 12 de febrero, las manifestaciones posteriores, y la crisis política que vivimos. Trato de mostrar el abismo con casos y cifras.

\section{E1 12 de febrero como Kristallnacht}

La enorme manifestación del 12 de febrero fue pacífica y especialmente concurrida por jóvenes, pues se celebraba el Día de la Juventuá. Llegó a la Plaza Carabobo, frente al Ministerio Público. Dirigentes estudiantiles y varios dirigentes políticos, entre ellos Leopoldo López y María Corina Machado, se dirigieron a la multitud. Concluidos los discursos, y después de la invitación a regresas a sus casas por Leopoldo López, orador de cierre, y del retiro de los líderes, las bandas armadas del gobierno y la Guardia Nacional atacaron a los manifestantes rezagados. Varias patrullas de la policía judicial fueron incendiadas, las puertas de vidrio de las oficinas del Ministerio Público fueron destruidas y hubo escenas de saqueo en la planta baja. Hubo dos muertos: el estudiante Bassil Da Costa y el "dirigente comunitario" Juan Montoya. Montoya era oficial de la policía de Caracas y dirigente del Colectivo Carapaica, una banda armada. Un número de estudiantes fueron capturados. La acción represiva de la Guardia Nacional se extendió en el vecindario y un joven ingeniero que tomaba fotografías de los eventos fue también asesinado. Poco después Diosdado Cabello, Presidente de la Asamblea Nacional, responsabilizó al imperialismo norteamericano y la derecha fascista de la violencia y las muertes.

La versión de Cabello, asumida luego por el Presidente Maduro, no coincide con lo que vimos en la televisión ni con los relatos de los testigos presenciales. Conforme informó el mismo Maduro, la experticia balística mostró que la bala que

\footnotetext{
${ }^{5}$ El Día de la Juventud conmemora la batalla que el 12 de febrero de 1814 las fuerzas independentistas venezolanas, reforzado con jóvenes estudiantes de la Universidad de Caracas y el Seminario de Santa Rosa, ganaron una batalla al ejército monárquico pro-español en La Victoria. Ese día se ha convertido en un día de fiesta para celebrar la juventud y la libertad. El gobierno convocó también a una marcha de jóvenes que resultó mucho más pequeña y se desarrolló sin incidentes.
} 
mató al dirigente comunitario y a los estudiantes fueron disparados por la misma pistola. Según las primeras informaciones lo hizo el agente del SEBIN - Servicio Bolivariano de Inteligencia (la policía política) - Adolfo Acosta (MEDINA, 2014). Sin embargo, la versión oficial se mantuvo. Se dictó orden de captura a Leopoldo López y se lo ha acusado de graves delitos. Está en la prisión militar de Ramo Verde. En la historia oficial los violentos están en la oposición.

\section{Apagando las candelitas}

En 5 de marzo, Presidente Maduro ordenó que "candelita que se prenda, candelita que se apague". La misión de apagar las candelitas correspondía a la Guardia Nacional, a las policías y a las bandas armadas, cuya misión es defender la revolución. La noche del 6 de marzo de 2014 en Los Ruices, una zona de clase media (o mediabaja) al Este de Caracas, las bandas armadas se presentaron para destruir las guarimbas y los vecinos respondieron con piedras, botellas y bombas molotov. Las bandas armadas invadieron varios edificios y hubo disparos. Resultado: dos muertos y un número indeterminado de vecinos fueron detenidos, al parecer algunos sin relación con los acontecimientos. Esa misma noche la Guardia Nacional también actuó en Chacao. El alcalde de la zona informó que se desplazaron 10 carros blindados ("tanquetas") y que actuaron más de 300 guardias. Cinco automóviles estacionados fueron chocados y 2 motocicletas destruidas. Los guardias lanzaron bombas lacrimógenas a los edificios donde sonaban cacerolas (EL NACIONAL, 2014a) [07 de marzo de 2014]. El Nacional recoge también que "a casi todos los detenidos los roban”, incluyendo la fotoperiodista italiana Francesca Commisari, a quien detuvieron y le robaron la cámara. Tres días después se ofrecía en venta por Internet. Para ese momento El Nacional informó que tras 22 días protesta iban 22 muertos y 1.322 detenciones.

Comportamiento ejemplar. La raíz de la muerte de un oficial de la Guardia Nacional por presunto disparo de un francotirador, el Presidente Maduro, en un discurso en televisión, ordenó a la Guardia Nacional allanar las viviendas de la urbanización El Trigal, en Valencia. La orden fue cumplida (EL NACIONAL, 2014b y 2014c; EL UNIVERSAL, 2014a y 2014b) [14 y 15 de marzo de 2014] y varias personas detenidas en sus viviendas sin orden judicial. "Ataque de motorizados causó tres muertos y 15 heridos en Valencia" (ROMERO, 2014, s/p) [13 de marzo de 2014]. El Presidente Maduro y el Vicepresidente Arreaza calificaron de ejemplar el comportamiento de los colectivos o bandas armadas. El Nacional (2014b) [14 de marzo de 2014] mostró seis fotografías de miembros de las bandas blandiendo o disparando armas. "Ocho universidades fueron atacadas en cuatro días" 
(SAAVEDRA y AVENDAÑO, 2014, s/p). En unos de esos ataques 16 hombres armados entraron a la Facultad de Ciencias de la Universidad Central de Venezuela y golpearon y robaron a dos estudiantes (SAAVEDRA y AVENDAÑO, 2014) [15 de marzo de 2014]. El ataque contra la Facultad de Arquitectura de la misma universidad fue peor: los hombres armados atacaron una reunión de estudiantes, obligaron a desnudarse a hombres y mujeres, los golpearon y destruyeron mobiliario, puertas y ventanas y puertas de vidrio. Sobre la pared dejaron un letrero: "Esta mierda es de la izquierda. Viva Chávez" (EL UNIVERSAL, 2014c, s/p) [21 de marzo de 2014]. En el titular del 7 de mayo de 2014, El Nacional destaca que "PNB, GNB y colectivos han atacado, saqueado y quemado 18 universidades" (OSÍO, 2014, s/p). Sin embargo, el gobierno insiste que los colectivos son pacíficos y su comportamiento ejemplar. Los Guardias Nacionales, que golpean y torturan a civiles desarmados, son elogiados por "valientes". Estas distorsiones del lenguaje (y de la verdad) son parte del conflicto vivido (GONZÁLEZ DELUCA, 2014).

\section{Sobre el abismo: cifras y conceptos}

Los altos funcionarios del estado generan cifras y conceptos con los cuales explican y justifican su acción. A un mes de iniciada la crisis el Presidente Maduro responsabilizó a Voluntad Popular (partidos de oposición liderado por Leopoldo López) y las policías municipales de estar detrás de las muertes (EL UNIVERSAL, 2014d) [13 de marzo de 2014], algo muy poco creíble. La Fiscal General de la República Luisa Ortega Díaz es seguramente la más articulada de los altos funcionarios y su estrategia es presentar la acción del Ministerio Público en cifras para que se pueda apreciar el esfuerzo y la imparcialidad del Ministerio Público. El 28 de marzo informó que desde el 12 de febrero hasta ese día, se habían producido 37 fallecidos y que los acontecimientos habían producido la reacción adecuada del Ministerio Público, pues habían 81 personas investigadas por violación de derechos humanos: 75 por trato cruel, 2 por tortura, 2 por homicidios consumados y 2 homicidios frustrados. Como resultado de esas investigaciones 17 funcionarios de cuerpos militares y policiales estaban detenidos, 3 estaban con medidas cautelares y había 7 órdenes de captura que todavía no se habían hecho efectivas. Entre los funcionarios detenidos había 7 del SEBIN (policía secreta), 4 de la Policía Nacional, 2 de las policías regionales (Mérida y Miranda), 2 de la Policía Municipal de Chacao, 1 Guardia Nacional. El cuerpo más represivo a la vista de todos es la Guardia Nacional, pero sólo uno de sus integrantes ha sido detenido. Tampoco fueron detenidos integrantes de las bandas armadas aunque han disparado frecuentemente armas de fuego a los manifestantes. 
En 10 de abril de 2014 (FISCALÍA, 2014) la Fiscal General proveyó nuevas cifras: 39 fallecidos y 650 lesionados. Entre los fallecidos, 31 son civiles y 8 funcionarios policiales o militares; 191 personas han sido acusadas de distintos delitos; 174 han sido privadas de libertad. Se investigan 120 casos de violación de derechos humanos (3 por homicidio, 2 homicidios frustrados, 2 por tortura y 113 por trato cruel) y "en algunos casos" se presentaron actos conclusivos. A los 96 días de protesta El Nacional informó de 44 muertos, 3080 detenciones y 164 presos (EL NACIONAL, 2014d) [19 de mayo de 2014]. A cuatro meses de iniciadas las protestas 3.127 personas habían sido detenidas, una magnitud sin precedentes, pues en los 14 años de gobierno de Chávez sólo se habían detenido 4.109 personas (VENEZUELA, 2014). Se abrieron 2.463 procesos penales contra los manifestantes acusándolos de distintos delitos (VENEZUELA, 2014). La mayor parte de esos procesos penales se mantienen abiertos, aunque el número de detenidos ha caído a pocas decenas.

Las cifras del Ministerio Público podían llevar a la confusión a quien no siguiera las noticias día por día. Los policías municipales de Chacao fueron detenidos porque mataron a una funcionaria del SEBIN. El incidente tuvo amplia cobertura porque un joven que caminaba solo por una calle de los Palos Grandes (Chacao y Caracas) con dos bolsas de supermercado que contenían alimentos fue abordado por personas que iban en un automóvil privado y fue introducido a la fuerza en el vehículo. Los vecinos que vieron la escena tomaron fotografías y avisaron a la policía municipal de Chacao porque entendieron que se trataba de un secuestro. La policía municipal en pocos minutos localizó el automóvil y una patrulla le ordenó detenerse, pero éste se dio a la fuga. La patrulla policial logró detener el automóvil de los presuntos secuestradores y se produjo un intercambio de disparos. Murió una mujer que iba en el asiento delantero y que resultó ser funcionaria del SEBIN. Los miembros de la policía de Chacao que iban en la patrulla fueron detenidos y están acusados de homicidio, pero el Ministerio Público no prestó ninguna atención la forma absolutamente irregular como fue detenido el joven que caminaba pacíficamente en la calle. A este joven no se le pidió identificación y todo hacía presumir que se trataba de un secuestro. Ese patrón de conducta de los funcionarios del SEBIN es el usual: detiene y somete a interrogatorios a ciudadanos sin orden judicial, allana viviendas y, en general, no respeta las reglas establecidas en la materia (ZERPA, 2014).

Nairobi Pinto es la periodista jefe de corresponsales de Globovisión, una estación de televisión especializada en noticia. Por varios años fue el medio de expresión de los opositores, pero sometida a un cerco de multas y presiones, fue 
vendida a empresarios poco conocidos vinculados con el gobierno. De todas maneras, su razón ser es proveer noticias lo que no siempre agrada al gobierno. Nairobi fue secuestrada a las puertas de su casa, frente a amigos y familiares, por personas encapuchadas y fuertemente armadas. Una semana después fue liberada en una ciudad-dormitorio cercana a Caracas y presentada en televisión por el Ministro del Interior y Justicia, quien habló de los grandes esfuerzos del gobierno para localizar y liberar a Nairobi. Fue bien tratada y le proveyeron tres comidas al día. Sus captores no se comunicaron con la familia ni pidieron rescate. Ha habido otros casos de estos secuestros extraños. Según el ministro se está investigando quiénes fueron sus captores y no hay ninguna información para no entorpecer las investigaciones (MATAMOROS, 2014; MAYORCA, 2014) [15 de abril de 2014]. La familia de Nairobi no es adinerada ni ella tiene ninguna notoriedad política, pero no hay que ser demasiado perspicaz para entender cuál es el mensaje, quién lo envía y a quiénes se les envía. Nairobi no ha hablado y fue compensada con un cargo diplomático fuera de Venezuela.

El Foro Penal, una ONG que ha sido muy activa en la defensa de los detenidos, presentó sus propias cifras sobre la acción represiva. Este informe habla de 1973 detenciones de las cuales ellos han tenido noticia, 371 personas lograron libertad plena y 1009 han quedado en libertad pero con medidas cautelares; 86 han sido privados de libertad (BASTA, 2014) [28 de marzo de 2014]. El Nacional (AVENDAÑO y ZERPA, 2014) [30 de marzo de 2014] en un reportaje de investigación, informa de 1825 detenciones, 1447 personas tienen expedientes penales abiertos, 85 han sido privados de libertad, 378 personas fueron puestas en libertad plena, 312 son casos por verificar y 138 son retenciones (AVENDAÑO y ZERPA, 2014). El 95 por ciento de las personas con procesos penales son estudiantes y los delitos varían. Los mencionados más frecuentemente son asociación para delinquir y obstrucción de vía pública. También hay acusaciones de terrorismo. Las medidas cautelares a las que son sometidos son muy variadas. Las más frecuentes son prohibición de participar en manifestaciones públicas y presentación periódica en el tribunal. Es bueno comentar algunos casos porque los excesos en la represión han sido notorios.

El caso Marvinia. Marvinia Jiménez no era una manifestante sino que es una mujer de unos 30 años que tomó fotografía con su teléfono celular mientras la Guardia del Pueblo reprimía a los manifestantes en la Isabelica, Valencia, el 24 de febrero de 2013. Esto fue suficiente para que se dirigieran a ella, la derribaran, y una vez en el piso la patearan. Josneidy Nayarit Castillo, integrante uniformada de la Guardia del Pueblo se montó sobre ella y con su casco le golpeó reiteradamente, 
desfigurándola y causándole lesiones graves. La acción fue filmada y las fotografías fueron publicadas. También se publicaron las fotografías del rostro desfigurado de Marvinia. El Ministerio Público no imputó a Josneidy sino Marvinia por tres delitos, uno de los cuales fue agresión contra tres miembros de la Guardia del Pueblo (FORO, 2014) [27 de febrero de 2014]. Posteriormente Josneidy fue condecorada por el Presidente.

El caso Massiel. No todos los apresados son estudiantes o sus simpatizantes. Massiel Pacheco Miranda es una joven vendedora de perros calientes en el Parque Miranda. Cerca de su carrito encontró una bolsa que contenía unos niples (bombas muy rudimentarias) y avisó al puesto cercano de la Guardia Nacional. Aparentemente no le prestaron atención, pero horas después llegó una patrulla policial que la detuvo. Luego, el Ministerio Público la acusó de terrorismo. El caso es tan patético que ha producido editoriales o reportajes de varios periódicos de Caracas (DERECHOS, 2014; CASTILLO, 2014) [09 de abril de 2014]. Aproximadamente un mes después el caso fue sobreseído.

La Defensora del Pueblo y la tortura. Conforme a la constitución corresponde a la Defensoría del Pueblo la promoción, defensa y vigilancia de los derechos humanos y los derechos consagrados constitucionalmente (VENEZUELA, 1999), una tarea enorme en el tiempo que vivimos. La Defensora del Pueblo optó por la vía semántica y prefirió señala que no veía casos de tortura pues sólo se comete ese delito cuando los maltratos tienen como finalidad la extracción de confesiones (DEFENSORA, 2014) [09 de marzo de 2014]. Ella condena la tortura, pero no se está torturando a nadie. Lo que existe son maltratos y se están tomando las acciones correctivas. Los muertos son responsabilidad de los guarimberos, no de la Guardia Nacional ni de las bandas armadas. El Centro de Derechos Humanos de la Universidad Católica Andrés Bello (CDH, 2014) preparó un informe basado en entrevistas a los estudiantes que describe con detalle el tratamiento que los estudiantes han venido recibiendo de la Guardia Nacional ${ }^{6}$. La definición de la Defensora del Pueblo no sólo no toma en cuenta la definición de tortura en los tratados internacionales sino que no muestra la preocupación que puede esperarse de tal funcionaria ante la crueldad de las conductas de los funcionarios.

\section{Justicia e injusticias}

En cualquier sociedad democrática regida por el derecho corresponde a fiscales, jueces y órganos como la Defensoría del Pueblo garantizar que los derechos

\footnotetext{
${ }^{6}$ Centro de Derechos Humanos (UCAB, 2014), resumen en Olivares (2014).
} 
de las personas sean respetados. Es decir, deben proteger a los ciudadanos y castigar a los funcionarios que abusen de su función. Claramente este no es el caso de Venezuela. Quienes tienen esas funciones según la constitución están clara y desembozadamente aliados con el gobierno en la represión de quienes protestan, sin respetar principios jurídicos ni la verdad material. Por ejemplo, tres estudiantes fueron acusados de posesión de sustancias incendiarias cuando en el acta policial de aprehensión no aparecía que hubieran tenido ninguna (Información verbal) ${ }^{7}$. Se detenía a personas que no estaban cometiendo delito y se lo hacía sin cumplir las formalidades de orden de aprehensión. Los detenidos eran usualmente incomunicados y sólo se les permitía un primer contacto con un abogado en el pasillo del edificio de los tribunales, unos minutos antes de ser presentados ante el juez (Información verbal) ${ }^{8}$. En esta sección se dará cuenta de la acción de los jueces, y especialmente del Tribunal Supremo de Justicia, usando unos pocos casos.

Diosdado vs María Corina. Panamá propuso que se convocara una reunión de cancilleres en la Organización de Estados Americanos para que se discutiera la situación de Venezuela. La moción fue derrotada y Venezuela rompió relaciones diplomáticas con Panamá. La diputada María Corina Machado fue designada representante alterno de Panamá para que pudiera presentar la situación de Venezuela en el Consejo Permanente de la organización. La diplomacia venezolana maniobró para que la reunión fuera privada y, en definitiva, para que la diputada Machado no pudiera hablar. Esta debió conformarse con hablar en una sala de prensa.

Debe advertirse que dar voz a la oposición por esta vía corresponde a una práctica frecuente en América Latina. Venezuela hizo un gesto similar para que Manuel Zelaya, derrocado Presidente de Honduras, pudiera dirigirse a la OEA. El 25 de marzo de 2014 Diosdado Cabello, Presidente de la Asamblea Nacional, blandiendo la constitución, declaró que la diputada María Corina Machado había aceptado un cargo público en Panamá y que, siendo esto incompatible con la condición de diputado, se había excluido de la Asamblea Nacional. Prohibió públicamente que ingresara a la Asamblea. La oposición solicitó que se discutiera el caso en sesión plenaria. Se negó tal petición pero la mayoría parlamentaria, aprobó sin discusión, la actuación de Cabello. Conviene advertir que la constitución venezolana pauta un procedimiento para la exclusión de un diputado que requiere la intervención del Tribunal Supremo de Justicia, debate parlamentario y de una mayoría de dos tercios de la Asamblea.

\footnotetext{
${ }^{7}$ Información de C. Alguindigue, quien ha actuado como abogada defensora.

${ }^{8}$ Información de C. Alguindigue, quien ha actuado como abogada defensora.
} 
Dos miembros de uno de los concejos municipales del Estado Miranda (Machado es diputada por ese estado), solicitaron amparo a favor de la diputada. La Sala Constitucional descartó la petición por falta de cualidad de los reclamantes pero dado el interés público del asunto y sin oír a la diputado Machado, dictaminó que la acción de Cabello y de la Asamblea Nacional era conforme a la constitución?.

Alcaldes penalizados. Varios ciudadanos solicitaron a la Sala Constitucional amparo contra los alcaldes de la oposición para que éstos garantizaran el libre tránsito y removieran los obstáculos en las vías públicas, algo en lo cual la Guardia Nacional, la Policía Nacional y las bandas armadas habían fracasado. La Sala atendió la solicitud de amparo y ordenó lo conducente a los alcaldes. La Sala constató como un hecho notorio comunicacional (pero sin citar las fuentes consultadas) que el Alcalde de San Diego (Valencia, centro de Venezuela) Enzo Scarano no había cumplido lo ordenado, lo citó a comparecer, lo condenó a 11 meses de prisión y lo destituyó del cargo. Igual suerte y pocos días después corrió el Alcalde de San Cristóbal (sur oeste de Venezuela), Daniel Ceballos. Se usó el mismo procedimiento. Ambos alcaldes son de la oposición. No importa que las pequeñas policías municipales carezcan de equipos anti-motines y que la Guardia Nacional, que sí los tiene, hubiera fracasado antes. Por otra parte la Sala carece de competencias penales y los alcaldes fueron condenados sin juicio y sin pruebas. La decisión de la Sala no tiene apelación. El argumento de la Sala es que la condena a prisión es una sanción disciplinaria, no realmente una pena, pero como pena accesoria los destituyó del cargo y ordenó la convocatoria de nuevas elecciones ${ }^{10}$. La oposición respondió con protestas y manifestaciones en casi todas las ciudades.

La prohibición del derecho a manifestar y la criminalización de la protesta. La Constitución (artículo 68) prevé el derecho a manifestar pacíficamente y la Ley de Partidos Políticos, Reuniones Públicas y Manifestaciones establece que los organizadores de manifestaciones deben participar a las autoridades municipales con 24 horas de anticipación. Sólo se requiere autorización cuando un acto administrativo general ha prohibido las manifestaciones en ese lugar. La Sala Constitucional del Tribunal Supremo, en sentencia 276 de 23 de abril de 2014, actuando ante una petición de interpretación del alcalde pro-gobierno del Municipio Guacara del Estado Carabobo, interpretó la ley en el sentido de requerir autorización municipal para todas las manifestaciones e hizo responsables civil y penalmente a los organizadores de

\footnotetext{
${ }^{9}$ Análisis jurídico en Nikken (2014).

${ }^{10}$ Información en todos los periódicos del país entre el 20 y 30 de marzo 2014. Análisis jurídico en Brewer-Carías (2014a).
} 
lo ocurrido en manifestaciones no autorizadas. El derecho a manifestar quedó así sometido a la voluntad de los alcaldes. Esto constituye el "secuestro del derecho político de manifestar"11 y es un claro atentado contra la democracia.

En la práctica esta prohibición no es demasiado relevante porque la protesta ya había sido criminalizada por el Código Penal en su reforma de 2005. Por ejemplo, en el artículo 357 se tipificó como delito el cierre de calles calles (VENEZUELA, 2000). El Ministerio Público generalmente usa otros tipos delictivos con penas mayores. Por ejemplo, manifestantes que acampan pacíficamente en una plaza son acusados de tenencia de drogas o de armas de fuego. Se hace fotografía no sólo de las armas decomisadas sino de billetes de dólares para sustentar la acusación que potencias extranjeras les pagan por manifestar. También se acusa a los manifestantes de asociación para delinquir y de terrorismo, delitos previstos en la Ley contra la delincuencia organizada y financiamiento del terrorismo.

La delgada piel de Cabello. El Universal (JUEZA, 2014) [07 de marzo de 2014] informó que el Tribunal 29 de Control de Caracas admitió la querella de Diosdado Cabello contra un articulista y la directiva del diario Tal Cual. El articulista había atribuido a Cabello la frase "si no les gusta la inseguridad, váyanse". Esa frase había sido divulgada por un medio, pero Cabello negó haberlo dicho. Conforme a la juez esto puede constituir difamación agravada, prohibió la salida del país e impuso otras medidas contra el articulista y la directiva del diario. El director del diario es Teodoro Petkoff, un importante dirigente socialista en el pasado, ahora dedicado al periodismo, y muy crítico del gobierno. Cabello es el Presidente de la Asamblea Nacional, Vice-Presidente del Partido y segundo (algunos dicen que el primer) hombre del régimen.

En resumen, el sistema de justicia, especialmente los fiscales del Ministerio Público y los jueces, están actuando como parte del aparato represivo que criminaliza la manifestación pública y la opinión. Los supuestos crímenes de los manifestantes son variados. Por ejemplo, los jóvenes que acamparon frente al PNUD (Programas de las Naciones Unidas para el Desarrollo) en la Avenida Miranda en Los Palos Grandes, en la Plaza Sadel de las Mercedes y en Chacao fueron apresados en una operación en una madrugada y se les imputó ocho delitos entre los cuales estuvo porte ilícito de armas de fuego, tráfico de drogas, uso de adolescentes para delinquir y asociación para delinquir (EL UNIVERSAL, 2014e) [12 de mayo de 2014]. Aun organismos que se suponen ocuparse de los derechos humanos, como la Defensoría del Pueblo, están

${ }^{11}$ Análisis jurídico en Brewer-Carías (2014b, s/p). 
claramente del lado de la represión. De seguidas analizaremos cómo esto ha sido posible.

\section{Leçon de tenèbres}

He tomado este título de la música barroca francesa para la parte analítica del trabajo. Las tinieblas en referencia son las producidas por la pérdida de independencia de jueces y fiscales y en definitiva la desaparición de las garantías institucionales y de lo que usualmente llamamos el estado de derecho. Creo que el caso de Venezuela no es único aunque tiene algunas peculiaridades y que hay lecciones que podemos aprender de él.

\section{La metáfora de la demolición}

Creo que debemos la metáfora de demolición Allan Brewer-Carías (2005). La metáfora supone que Venezuela del período 1958-1998 era un estado de derecho, un estado social de derecho, y que la revolución iniciada en 1999 demolió tal construcción. Es una metáfora atractiva porque ha habido un proceso de destrucción y de transgresión de los principios básicos del estado derecho. Por ejemplo, ha sometido abiertamente a los jueces, o crea delitos o modifica el Código Orgánico Procesal Penal, materias de reserva legislativa, por decretos leyes. Aplica el derecho sin consideración a principios bien establecidos o la verdad material, pero puede ser una metáfora engañosa porque supone que existía un saludable estado de derecho que fue destruido y sugiere que no queda nada en su lugar. El esfuerzo requerido es mostrar qué fue lo destruido y también qué ha quedado.

El estado de derecho es un tipo ideal, en sentido weberiano. En su experiencia histórica, los estados pueden acercarse o alejarse de ese modelo. En todos, o casi todos los países, se usa el derecho como instrumento de regulación social y política, pero el respeto del principio de legalidad y de los derechos humanos, característicos del estado de derecho, se hace con mayor o menor intensidad en los distintos países. En ese sentido, los países del mundo pueden colocarse en un ranking de mayor o menor respeto de los principios del estado de derecho (AGRAST et al., 2013), aunque tal esfuerzo generalmente genera discusión y descontentos.

Venezuela 1958-1998 se consideraba una de las democracias más sólidas del continente, con partidos políticos fuertes, elecciones universales y libres y amplia participación electoral de la población. Rey (1972) describió la democracia venezolana como un sistema de conciliación de elites en el cual los partidos políticos jugaban un papel fundamental. Naim y Piñango (1984) lo describieron como una ilusión de armonía, pues los actores principales podían entenderse entre ellos, pero 
donde no existían árbitros que pudieran dirimir sus diferencias. El estado de derecho como tal podía considerarse como bastante débil (PÉREZ-PERDOMO, 2003). La elite política le prestaba poca atención a las tareas legislativas (NJAIM, 1996; PÉREZ-PERDOMO, 2003) y el aparato de justicia era un apéndice poco importante de los partidos (PÉREZ-PERDOMO, 2003 y 2011). Como consecuencia, no cumplía con la función de proteger los derechos de los ciudadanos. Estos, especialmente los de bajos ingresos, eran vulnerables a los peores abusos de la policía y del propio sistema judicial (PÉREZ-PERDOMO, 1985). La previsibilidad de la conducta de los funcionarios venía del sistema político y del complejo sistema de relaciones interpersonales de la sociedad venezolana, no del sistema de reglas ni de la aplicación imparcial de éstas. La justicia, penetrada por los partidos y redes de corrupción, cumplía un papel marginal en la regulación de las relaciones de negocios (PÉREZ-PERDOMO, 2011).

En la década de 1990 el sistema político entró en crisis (ÁLVAREZ, 1996; KORNBLITH, 1998) y el debilitamiento de los partidos permitió que la Corte Suprema de Justicia asumiera un papel de árbitro de la vida política y social venezolana (PÉREZ-PERDOMO, 2011). Pero el entero aparato de justicia tenía una reputación generalizada de ineficiencia y corrupción. Hubo esfuerzos de fortalecer el estado de derecho mejorando el proceso legislativo e iniciando una reforma de la justicia, que probablemente fue tarde y poco (PÉREZ-PERDOMO, 2004).

La crisis de la democracia venezolana explica la elección del Teniente Coronel Hugo Chávez, un outsider en la política venezolana, como Presidente de la República. Su proyecto político de "refundar la República" era bastante radical, pero nadie lo tomó muy en serio, acostumbrados como estábamos a los forcejeos y negociaciones entre políticos. En 1999 Chávez asumió la presidencia, logró convocar la Asamblea Nacional Constituyente e inició un cambio político radical que ha tenido varios nombres, pero que hoy podemos llamar la Revolución Chavista.

Chávez siguió políticas populistas de reparto de la riqueza petrolera y de políticas hostiles a la burguesía venezolana y a las inversiones extranjeras, especialmente a las provenientes de los Estados Unidos y Europa. Expropió o se apropió crudamente de empresas y propiedades rurales y urbanas, siguió políticas extremadamente intervencionistas que limitaron la inversión privada y paralelamente persiguió el sindicalismo libre.

Sus políticas generaron una fuerte reacción, especialmente en los grupos altos y medios. En 2002, después de grandes manifestaciones públicas, los generales intentaron un golpe de estado que no tuvo éxito. Esto lo llevó a una política que llamó de radicalización de la revolución. En 2004 logró el completo control de la 
Asamblea Nacional, el Tribunal Supremo de Justicia y de todas las instancias del poder. Curiosamente el sistema político que surgió fue un tipo de estado dual (FRAENKEL, [1941] 1996). Así, al lado de las fuerzas armadas tradicionales, se creó una milicia que le responde personalmente al Presidente. Para el control político, al lado de la policía se crearon las bandas armadas. Lo mismo ocurrió respecto al sistema de salud, creando "misiones" manejadas por médicos cubanos. En educación hay escuelas bolivarianas y universidades paralelas a las tradicionales sobre las cuales se ejerce un estricto control político. Existen también sistemas paralelos de crédito y de comercialización de alimentos, línea blanca y otras comodidades. La idea central es que los organismos paralelos están menos regulados por el derecho, están manejados por personas de confianza política y más sometidos al líder político ${ }^{12}$.

El efecto que esto ha tenido sobre el derecho y la cultura jurídica y política ha sido deletéreo (PÉREZ-PERDOMO, 2009; AZUELA, 2011). A los esfuerzos de la oposición de abrir debates políticos en la Asamblea Nacional se ha respondido con la violencia. La legislación no se debate. Los diputados de oposición han sufrido agresiones físicas graves. La judicatura ha sufrido depuraciones sucesivas y está estrictamente controlada. En el caso más grave, una juez penal que tomó una decisión que molestó al Presidente generó que éste fuera a la televisión en diciembre 2009 y ordenara que se la detuviera y condenara a 30 años de prisión por corrupción, no importando que esa no sea la pena legal para la corrupción y que el delito no se comprobara. En la cárcel de mujeres fue violada y sometida a todo tipo de vejaciones, se le negó asistencia médica a pesar de graves problemas de salud (OLIVARES, 2012). Organismos de Naciones Unidas y organizaciones de jueces y abogados de todo el mundo solicitaron la libertad de la juez Afiuni, pero el régimen ha sido inflexible. Desde junio 2013 se le sigue juicio en libertad condicional, aunque no está muy claro cuál fue su delito. Los jueces han pasado a ser empleados gubernamentales de segundo orden que deben mostrarse leales y severos a la hora de perseguir enemigos políticos del régimen, y deben cuidarse de no molestar a los aliados.

La criminalidad violenta se ha incrementado substancialmente porque las bandas armadas son protegidas por el gobierno e incontrolables por la policía y la justicia. Delitos como el homicidio y el secuestro se han hecho comunes (BRICEÑO

12 Rafael Simón Jiménez observó sobre una versión temprana de este trabajo que los grupos parapoliciales o paramilitares tienen la ventaja, a los ojos de los gobernantes, de no responsabilizarlos por sus acciones (Información verbal). En definitiva es "el pueblo" quien ataca a los manifestantes. Esto seguramente refleja la opinión de los decisores, pero es bueno observar que tribunales internacionales generalmente responsabilizan a quienes ejercen en poder por la acción de estas bandas. 
LEÓN, 2012). Las prisiones pasaron a ser controladas por los delincuentes más violentos (denominados pranes) con los cuales el gobierno negocia abiertamente.

La situación ha afectado especialmente a la justicia penal que ha vuelto a los peores hábitos de discrecionalidad, abortando el esfuerzo de introducir un sistema acusatorio más transparente que se inició en 1998, pero que fue de corta duración (ALGUÍDIGUE y PÉREZ-PERDOMO, 2013). En la justicia administrativa prácticamente todas las decisiones son favorables a la administración (CÁNOVA GONZÁLEZ, 2009). La ocupación de propiedades rurales y urbanas por grupos armados que se reclaman del chavismo son frecuentes.

En 2010, la Presidenta del Tribunal Supremo Luisa Estela Morales criticó la separación de poderes, pues la revolución necesita mejor coordinación y unidad de mando.

En resumen, nadie está a salvo de una delincuencia desatada ni de los abusos de los funcionarios. Sólo la protección política puede hacer una diferencia. Ella puede garantizar la impunidad o el tratamiento favorable. A la vez quien sea considerado enemigo puede esperar el tratamiento severo, sin importar demasiado lo que la constitución y las leyes garanticen. La pregunta es qué queda del derecho en estas circunstancias. La respuesta está en la siguiente y última sección del trabajo.

\section{Lo que queda del derecho}

Hobbes ([1651]1968) se planteó cómo sería la sociedad si suprimimos el estado y el derecho. Él señaló que como no podemos hacerlo, tenemos que desarmar imaginariamente el complejo sistema de relojería de la sociedad para ver qué tendríamos y cómo funcionaría. Todos conocemos su respuesta: quedarían individuos provistos de derechos ilimitados, lo que conduce a la violencia generalizada, a la guerra de todos contra todos. Es el estado de naturaleza.

La revolución chavista ha hecho mucho por destruir el derecho en la realidad. La legislación ya no es una regla vinculante para todos, y ajustar su conducta a ella tampoco es garantía de tener la protección del estado. Los jueces están obligados a cumplir las órdenes del poder político, o de adivinar sus deseos. Imparcialidad y debido proceso son expresiones en los libros, no en las prácticas judiciales. En cierta forma, la revolución también ha destruido el estado en el sentido que ya no tiene el monopolio de la fuerza. Las bandas armadas dependen del partido Socialista Unido de Venezuela, pero sus dirigentes no tienen capacidad de controlar todas sus actividades. Policías, fiscales y jueces saben que esas bandas tienen protección política y prefieren no interferir en sus actividades, a menos que tengan una orden muy específica del poder político. 
Algo de lo previsto por Hobbes ha ocurrido: ha aumentado la violencia, han disminuido las inversiones, el derecho de propiedad se ha debilitado, el país se ha empobrecido. Pero no es la guerra de todos contra todos. La vida continúa: las personas van al cine, al teatro, a los restaurants, aunque limitan los sitios a frecuentar y las horas a las cuales se sale. La industria y el comercio funcionan aunque con poca inversión. Las personas y negocios celebran contratos y generalmente los cumplen. Pero la vida es más impredecible y peligrosa. Las medidas de protección personal se extreman: automóviles blindados, guardaespaldas, protección eléctrica o de rejas, viviendas fortificadas. Cada familia toma las precauciones según sus ingresos y percepción de peligro.

En materia de negocios, se examina muy cuidadosamente con quién se hace negocios y se usan o se crean vínculos sociales que eviten los conflictos o faciliten su regulación fuera de la justicia formal. Para personas con menos aversión al riesgo, menos escrúpulos éticos o más protección política pueden surgir excelentes oportunidades de negocios, aunque los cálculos pueden resultar erróneos como un número de los llamados "boliburgueses" en prisión o en exilio podrían atestiguarlo. Algunas empresas brasileñas podrían enseñarnos de cómo hacer negocios en Venezuela. Por ejemplo, la empresa brasileña Odebrecht ha hecho enormes inversiones en Venezuela en estos años revolucionarios y se las ha arreglado para que no se atiendan los reclamos por daños ambientales de comunidades que conozco. Sería del mayor interés saber cómo han ganado los contratos cuando el sistema de licitaciones se dejó inoperativo, y cómo hace para no se mire a los daños ambientales y para que el gobierno de Venezuela, que es muy selectivo pagando deudas, pague las que tiene con ella.

En líneas generales, podría afirmarse que la realidad venezolana se acerca más al estado de naturaleza lockeano (LOCKE, 1997) que al hobbesiano. La mayor parte de las personas respetan la propiedad de los otros y cumplen sus obligaciones contractuales. Los contratos escritos tienen como misión más clarificar las obligaciones de las partes que servir de instrumentos para litigios eventuales. El litigio se evita. En los contratos generalmente se prevé la solución de conflictos por arbitraje. En otras palabras, en el ambiente de negocios, el derecho está al servicio de la ética. Las personas cumplen sus obligaciones no por temor a un posible recurso al aparato coercitivo sino por las consecuencias difusas que el incumplimiento acarrearía para su prestigio personal, lo cual es una dimensión ético-social. Pero como lo planteaba Locke, si un conflicto surge en esa especie de estado de naturaleza, no hay un mecanismo eficaz de resolverlo. Si el conflicto es con un organismo del estado, el ciudadano está totalmente indefenso. 
Lo que caracteriza la situación de inoperancia del derecho y la conversión del estado en un actor socio-político que no garantice los derechos de los ciudadanos ni pueda servir de árbitro para sus disputas es la desaparición de los mecanismos de tríada. La relación siempre es diádica y hay que buscar el apoyo de otros sistemas normativos como la ética, o directamente del poder, para lograr el cumplimiento de contratos y acuerdos. Cuando el conflicto es con el poder político, como lo es en la actualidad, no hay foro institucional para resolver el conflicto dentro del país. Quedan como recursos la violencia y los mecanismos internacionales.

La violencia tiene unos costos enormes que nadie razonablemente desea, pero regímenes que destruyen los mecanismos institucionales corren el riesgo de provocar la situación en la cual todos pierden, como lo muestran muchos casos. Siria y Egipto están entre los más recientes. La mediación internacional o la facilitación de la negociación con la ayuda de actores internacionales ha cobrado más importancia en estos tiempos de globalización, pero son mecanismos débiles. El gobierno de Venezuela denunció el Tratado Interamericano de Protección de Derechos Humanos y se ha negado a que la Comisión de Derechos Humanos de la Organización de los Estados Americanos visite el país, pero buscó el apoyo de UNASUR que, en definitiva, ha asumido un papel de facilitador del diálogo junto con el Vaticano. Aunque la fase aguda del conflicto político ha cesado, el conflicto social es latente porque el sistema económico ha colapsado y el conflicto político puede resurgir. Una posibilidad es que los actores internacionales tengan suficiente ascendencia sobre el gobierno para lograr acuerdos fundamentales que puedan evitar choques violentos. Esta vía está, todavía, en su inicio y hay considerable escepticismo entre muchos de que pueda funcionar.

En la perspectiva de este trabajo, interesa especialmente analizar cuáles aspectos del derecho continúan aunque no intervengan en el conflicto central. En Venezuela sigue operando una activa profesión jurídica. Hay abogados que se han convertido en operadores del nuevo sistema y han alcanzado posiciones muy importantes como magistrados del Tribunal Supremo. El oportunismo y la oportunidad de negocios lucrativos no deja de tener riesgos. El caso más emblemático es el del magistrado Aponte, que primero como Fiscal General Militar y luego como Presidente de la Sala Penal del Tribunal Supremo, le correspondió ordenar la protección de narcotraficantes o la condena de personas enteramente inocentes, pero que al régimen convenía condenar. Caído en desgracia y ante el grave peligro que corría su vida en manos de sus antiguos aliados, ha debido solicitar la protección de la DEA y convertirse en informante. Otros abogados más discretos se han convertido en lobistas o intermediarios para una multitud de negocios con el gobierno o con 
personas vinculadas al gobierno, pero varios han caído en desgracia y han debido irse al exilio.

Otro sector de la profesión ha permanecido independiente, pero su práctica ha tenido transformaciones y limitaciones importantes. La mayor parte de las firmas de abogados que surgieron en la segunda mitad del siglo XX se mantienen, pero no han crecido como lo han hecho sus contrapartes de Brasil, Argentina, México, Perú y Chile. Los abogados de estas firmas están muy conscientes de la limitación que para la práctica del derecho tiene la nueva situación (GÓMEZ y PÉREZ-PERDOMO, 2014).

Por último, hay un sector de la profesión que tradicionalmente defendía los derechos humanos. Este sector se ha enriquecido con otros grupos más activamente vinculados a la política. Han creado ONGs para la defensa de los derechos de los ciudadanos, o colaboran con los líderes de la oposición, o defienden frecuentemente pro bono los acusados por el régimen. Esto incluye un número de abogados de negocios transformados en defensores de los derechos humanos (GÓMEZ, 2010).

Entre los juristas académicos se perciben tendencias similares. Continúan publicando libros y artículos en revistas, algunos con más intensidad que otros. Quienes han salido en defensa de las acciones del régimen son muy pocos. Un grupo relativamente numeroso no parece haber registrado lo que ocurre en el país o tal vez prefiera ignorarlo. Se ocupan de la correcta interpretación del artículo 1250 del Código Civil, del concepto de culpabilidad o del pensamiento jurídico de Finnis. Un grupo, también numeroso escriben artículos o libros críticos de lo que ocurre o de las políticas o legislación del régimen. Por supuesto, los profesores seguimos enseñando derecho, aunque naturalmente cada profesor ha tenido que preguntarse qué enseñar y cómo hacerlo en las nuevas circunstancias (PÉREZ-PERDOMO, 2014).

El caso de Venezuela no es único. La experiencia de regímenes totalitarios y autoritarios ha sido bastante común aun en la historia reciente de la humanidad. En este apresurado planteamiento sólo dejo dos observaciones: la primera es que hay buenos estudios sobre el derecho y los jueces en el régimen autoritario del PRI (Partido Revolucionario Institucional) en México, en las dictaduras militares de Argentina, Brasil y Chile, en la España franquista, en Francia bajo Vichy, en la Italia fascista y en Alemania nazi, en la llamada República Democrática de Alemania, en China bajo Mao y en las condiciones de hoy. Conociendo parcialmente esa literatura, creo que se puede parafrasear a Dostoievski, y afirmar que cada sistema jurídico vive el autoritarismo a su propia manera, aunque comparativamente seguramente podemos hacer tipologías. 
La segunda observación y mi punto final es que cada comunidad profesional de juristas y, en definitiva, cada jurista individual, reacciona de distinta manera. Esto tiene que ver con la necesidad de seguir viviendo aun en los regímenes más adversos y, también, con el compromiso que cada uno tenga con los valores del derecho y de la democracia. El establecimiento o restablecimiento de la democracia y la consolidación del estado de derecho tiene que ver con cuán acendrados la población y, especialmente, los juristas tengamos estos valores y las acciones que tomemos. Nuestro pensamiento y nuestras acciones no son inocuos para libertad.

Rogelio Perez-Perdomo é Mestre em Direito pela Universidade de Harvard e Doutor em Ciências, menção em Direito, pela Universidade Central da Venezuela. Atualmente é Professor da Universidade Metropolitana em Caracas, Venezuela e atua como Professor visitante frequente da Escola de Direito da Universidade de Stanford (California, Estados Unidos). E-mail: rperez3@law.stanford.edu.

\section{Referências}

AGRAST, Mark David et al. The World Justice Project/Rule of law index 2012-2013. Washington: The World Justice Project, 2013.

ALGUÍNDIGUE, Carmen; PÉREZ-PERDOMO, Rogelio. Revolución y proceso penal en Venezuela 1999-2012. Anales de la Universidad Metropolitana, v. 13, n. 2, Caracas, 2013.

ÁlVAREZ, Angel (Ed.). El sistema politico venezolano. Crisis y transformación. Caracas: Universidad Central de Venezuela, 1996.

ANDERSON, Jon Lee. Slumlord - What has Hugo Chavez wrought in Venezuela. The New Yorker, Caracas, 28 jan. 2013. Disponível em: <http://www.newyorker.com/magazine/2013/01/28/slumlord>. Acesso em: 10 ago. 2014.

AVENDAÑO, Emily; ZERPA, Fabiola. Protestas, un detenido cada media hora. El Nacional, Caracas, Suplemento Siete Días, p. 1-4, 30 mar. 2014. Disponível em: <http://www.elnacional.com/siete_dias/BOADA-CICPC-COELLO-POLICHACAO-SEBIN-

VITALE_0_380962131.html>. Acesso em: 20 jul. 2014.

AZUELA, Antonio. Cultura jurídica y propiedad urbana en Venezuela. Caracas y las expropiaciones en la era del chavismo entre 2000 y 2009. Politeia, Caracas, v. 34, n. 46, p. 47-81, 2011.

BASTA de abusos. Tal Cual Digital, Caracas, 28 mar. 2014. Disponível em: $<$ http://www.talcualdigital.com/movil/visor.aspx?id=100821>. Acesso em: 15 jul. 2014.

BREWER-CARÍAS, Allan R. La condena y el encarcelamiento de alcaldes por la Sala Constitucional del Tribunal Supremo usurpando competencias de la jurisdicción penal, mediante un procedimiento 
sumario contrario a la constitución, y despojarlos de su investidura electiva. Revista de Derecho Público, Caracas, no prelo, 2014a.

. Un nuevo atentado contra la democracia: el secuestro del derecho político a manifestar mediante una ilegítima reforma legal efectuada por la Sala Constitucional del Tribunal Supremo. Artigo no prelo, 2014b. Disponível em: <http://www.allanbrewercarias.com/Content/449725d9-f1cb-474b-8ab241 efb849fea3/Content/Brewer.\%20Sobre\%20la\%20ileg\%C3\%ADtima\%20reforma\%20del\%20r\%C3 \%A9gimen\%20legal\%20del\%20derecho\%20a\%20manifestar\%20poir\%20la\%20Sala\%20\%20Constit ucional\%20abril\%202014.pdf>. Acesso em: 14 ago. 2014.

La progresiva y sistemática demolición de la autonomía e independencia del poder judicial en Venezuela (1999-2004). In: XXX Jornadas J.M. Domínguez Escovar, Barquisimeto, Venezuela, 6 jan. 2005.

BRICEÑO-LEÓN, Roberto et al. Violencia e institucionalidaa. Informe del Observatorio Venezolano de Violencia. Caracas: Alfa, 2012.

CANOVA-GONZÁLEZ, Antonio. La realidad del contencioso administrativo venezolano. Caracas: Funeda, 2009.

CASTILlO, Laura Helena. Massiel, de denunciante a terrorista. El Nacional, Caracas, Suplemento Siete Días, p. 1, 9 abr. 2014.

CDH. Centro de Derechos Humanos de la Universidad Católica Andrés Bello. Resultado de entrevistas a profundidad con detenidos sobre la libertad personal, debido proceso y alegaciones de tortura y malos tratos. Segundo informe de avance. Caracas: Universidad Católica Andrés Bello, 2014. (Emitido en 13 de marzo de 2014).

DEFENSORA culpó a manifestantes de mayoría de los muertos. El Nacional, Caracas, 9 mar. 2014. Disponível em: <http://www.el-nacional.com/politica/Defensora-culpo-manifestantes-mayoriamuertos_0_368963261.html>. Acesso em: 14 ago. 2014.

DERECHOS violados. Tal Cual Digital, Caracas, 09 abr. 2014. Disponível em: <http://www.talcualdigital.com/nota/visor.aspx?id=101365\&tipo=AVA>. Acesso em: 14 ago. 2014.

EL NACIONAL. Primera Página. Caracas, Venezuela, 07 mar. $2014 \mathrm{a}$.

. Primera Página. Caracas, Venezuela, 14 mar. 2014b.

. Primera Página. Caracas, Venezuela, 15 mar. 2014c.

. Primera Página. Caracas, Venezuela, 19 mayo 2014d.

EL UNIVERSAL. Primera Página. Caracas, Venezuela, 14 mar. 2014 a.

. Primera Página. Caracas, Venezuela, 15 mar. 2014b.

- Primera Página. Caracas, Venezuela, 21 mar. 2014c.

. Primera Página. Caracas, Venezuela, 13 mar. 2014d.

. Primera Página. Caracas, Venezuela, 12 maio $2014 \mathrm{e}$.

FISCALÍA acusa a otras 80 personas por violencia en el país. El Universal, Caracas, Venezuela, 10 abr. 2014. Disponível em: <http://www.eluniversal.com/nacional-y-politica/140410/fiscalia-acusa-a-otras80-personas-por-violencia-en-el-pais>. Acesso em: 17 jul. 2014.

FORO Penal: Es aberrante que imputaran a Marvinia Jiménez. El Universal, Caracas, 27 fev. 2014. Disponível em: <http://www.eluniversal.com/nacional-y-politica/protestas-en-venezuela/140227/foropenal-es-aberrante-que-imputaran-a-marvinia-jimenez>. Acesso em: 25 ago. 2014.

FRAENKEL, Ernst [1941]. The dual state: a contribution to the theory of dictatorship. New York: Oxford University Press, 2006.

GÓMEZ, Manuel A. Political activism and the practice of law in Venezuela. In: COUSO, Javier; HUNEEUS, Alexandra; SIEDER, Rachel (Eds.). Cultures of legality. Judicialization and political activism in Latin America. Cambridge: Cambridge University Press, 2010. 
GÓMEZ, Manuel A.; PEREZ-PERDOMO, Rogelio. Business lawyers in Venezuela: from globalization to the Chavista revolution. In: LSA - Law and Society Association Meeting, Minneapolis, May 2014.

GONZÁLEZ DELUCA, María Elena. Mentiras, dardos y tongue in cheek. Tal Cual, Caracas, Suplemento Literales, p. 15, 2014.

CANOVA-GONZÁLEZ, Antonio. La realidad del contencioso administrativo venezolano. Caracas: Funeda, 2009.

HOBBES, Thomas [1651]. Leviathan. Harmondsworth, UK: Penguin Books, 1968.

JUEZA dictó cautelares a Genatios y a la directiva de Tal Cual. El Universal, Caracas, 7 mar. 2014. Disponível em: <http://www.eluniversal.com/nacional-y-politica/140307/jueza-dicto-cautelares-agenatios-y-a-la-directiva-de-tal-cual>. Acesso em: 29 jul. 2014.

KORNBLITH, Miriam. Venezuela en los 96 . La crisis de la democracia. Caracas: Universidad Central de Venezuela y Ediciones IESA, 1998.

LOCKE, John [1690]. The second treatise of government. Indianapolis: Bobbs-Merrill Library of Liberal Arts, 1997.

MATAMOROS; Natalia. Nairobi: "Los captores nunca me tocaron ni me maltrataron". El Universal, Caracas, Venezuela, 15 abr. 2014. Disponível em: < http://www.eluniversal.com/sucesos/140415/nairobi-los-captores-nunca-me-tocaron-ni-memaltrataron>. Acesso em: 27 jun. 2014.

MAYORCA, Javier Ignacio. Persisten interrogantes en el caso de Nairobi Pinto. El Nacional, Caracas, 15 abr. 2014. Disponível em: <http://www.el-nacional.com/sucesos/Persisten-interrogantes-caso-NairobiPinto_0_391161096.html>. Acesso em: 27 jun. 2014.

MEDINA, Oscar. No era lo que decían. Reportaje periodístico. El Universal, Caracas, 2014.

NAIM, Moisés; PIÑANGO, Ramón. El caso Venezuela: una ilusión de armonía. In: NAIM, Moisés; PINÃNGO, Ramón (Directores del proyecto). El caso Venezuela: una ilusión de armonía. Caracas: Ediciones IESA, 1984.

NIKKEN, Claudia. Notas sobre el artículo 187.20 de la Constitución. Disponível em: $<$ http://www.acessoalajusticia.com>. Acesso em: 15 jul. 2014.

NJAIM, Humberto. La seguridad jurídica en el contexto político venezolano. In: BOZA, Maria Eugenia; PEREZ-PERDOMO, Rogelio (Comp.). Seguridad jurídica y competitividad. Caracas: Ediciones IESA, 1996.

OID. Observatorio Iberoamericano de la Democracia. La masacre del 12 de febrero o del Día de la Juventua. Buenos Aires, 2014.

OLIVARES, Francisco. Torturas en revolución. Golpes, descargas eléctricas, amenazas de violación y torturas sicológicas, aplicación de sustancias químicas, son algunas formas de tortura aplicadas a manifestante detenidos. El Universal, Caracas, p. 3-4, 20 abr. 2014. Disponível em <http://www.eluniversal.com/nacional-y-politica/140420/torturas-en-revolucion>. Acesso em: 29 jul. 2014.

. La presa del Comandante. La Hoja del Norte, Caracas, 2012.

OSÍO, Yoriana. 18 universidades han sido atacadas desde el 4-F. El Nacional, Barquisimeto, Venezuela, 7 maio 2014. Disponível em: <http://www.el-nacional.com/sociedad/universidadesatacadas_0_404359786.html>. Acesso em: 27 jul. 2014.

PÉREZ-PERDOMO, Rogelio. Las revistas jurídicas venezolanas en tiempos de revolución. No prelo, 2014.

. Violencia delictiva e instituciones. Un ensayo sobre crimen y justicia en Venezuela contemporánea.

Revista de Derecho. Consejo de Defensa del Estado, Santiago del Chile, n. 27, 2012.

- Justicia e injusticias en Venezuela. Caracas: Universidad Metropolitana y Academia Nacional de la Historia, 2011. 
. Derecho y cultura jurídica en Venezuela en tiempos de revolución (1999-2009). Cuaderno de la Fundación Manuel García Pelayo, Caracas, 2009.

. Reforma judicial, estado de derecho y revolución en Venezuela. In: PÁSARA, Luis (Ed.). En busca de una justicia distinta. Experiencias de reforma en América Latina. Lima: Consorcio Justicia Viva, 2004.

. Venezuela 1958-1999: the legal system in an impaired democracy. In: FRIEDMAN, Lawrence; PÉREZ-PERDOMO, Rogelio (Eds.). Legal culture in the age of globalization. Latin America and Latin Europe. Stanford: Stanford University Press, 2003.

. Asistencia jurídica y acceso a la justicia en Venezuela. In: PÉREZ-PERDOMO, Rogelio (Coord.). Justicia y pobreza en Venezuela. Caracas: Monte Ávila Editores, 1985.

REY MARTÍNEZ, Juan Carlos. El sistema de partidos venezolanos. Politeia, Caracas, n. 1, 1972.

ROMERO, Tibisay. Ataque de motorizados dejó tres muertos y 15 heridos en La Isabelica de Valencia. El nacional, Valencia, Venezuela, 13 mar. 2014. Disponível em: <http://www.elnacional.com/sucesos/Ataque-motorizados-muertos-Isabelica-Valencia_0_371363066.html>. Acesso em: 27 jul. 2014.

SAAVEDRA, Boris; AVENDAÑO, Emily. GNB y colectivos atacan universidades en todo el país. El Nacional, Caracas, 15 mar. 2014. Disponível em: <http://www.el-nacional.com/sociedad/GNBcolectivos-atacan-universidades-pais_0_372562995.html\#.UyRIBlGguNc.twitter>. Acesso em: 27 jul. 2014.

VENEZUELA. Venezuela 2014: Protestas y derechos humanos. Informe Febrero-Mayo. Diversas ONGs de derechos humanos. Caracas, 2014.

. Código Penal. Artículo 6, numeral 1 del Decreto de la Asamblea Nacional Constituyente, de 28 de marzo de 2000. Disponível em: <http://www.oas.org/juridico/spanish/mesicic3_ven_anexo6.pdf>. Acesso em: 25 jun. 2014.

. Constitución (1999). Constitución de la Republica Bolivariana de Venezuela de 1999. Disponível em: <http://www.tsj.gov.ve/legislacion/constitucion1999.htm>. Acesso em: 25 jun. 2014.

VON BERGEN, Franz. Los colectivos y el poder. El Nacional, Caracas, Reportaje de investigación, Suplemento Siete Días, p. 1-3, 2014.

ZERPA, Fabiola. ¡Abran! ¡Es el SEBIN! El Nacional, Caracas, Reportaje de investigación, Suplemento Siete Días, p. 1-3, 2014. Disponível em: <http://www.el-nacional.com/siete_dias/ARELLANO-DARIOFUNCIONARIOS-GLIDIS-SEBIN_0_409759164.html>. Acesso em: 27 jul. 2014.

Texto recebido em 17 de setembro de 2014. Aprovado em 16 de outubro de 2014. 